\title{
DETECTING DISASTER DAMAGE FROM 2015 TYPHOON ETAU BY THE COMBINED USE OF DIFFERENT SAR SATELLITES
}

\author{
Kenichi Honda ${ }^{a}$, Kei Fujihira ${ }^{a}$, Norichika Asada ${ }^{a}$, Ayumi Fukushima ${ }^{a}$,and Naruo Mushiake ${ }^{a}$ \\ ${ }^{a}$ Kokusai Kogyo CO.,Itd., 2-24-1 Harumicho, Fuchu City, Tokyo, (kenichi_honda, kei_fujihira, norichika_asada, ayumi_fukushima, \\ naruo_mushiake)@kkc-grp.jp
}

Commission VIII, WG VIII/1

KEY WORDS: SAR, Disaster Monitoring, Flood, Landslide, Sentinel-1, ALOS-2 PALSAR-2, COSMO-SkyMed

\begin{abstract}
:
In this study, focusing on the flood damages in Joso City in Ibaraki Prefecture, we estimated the extent of inundation using multiple SAR satellites and examined their varied results depending on observational bands. We further examined the potential utilization of combined different SAR data for initial responses to disasters. For classification of the inundated areas, a binary classification was used with a threshold of backscatter coefficient and the difference in backscatter coefficient between the usual condition and the situation after the breach. In the extraction of inundation after the breach of the levee, COSMO-SkyMed showed the accuracy of $72.6 \%$, while ALOS-2 PALSAR-2 indicated the accuracy of $66.1 \%$. The extent of inundation were extracted by difference of backscatter coefficient using the data taken by Sentinel-1 and ALOS-2 PALSAR-2 before the breach of the levee, and the comparison analysis results showed that the extent of inundation expanded after the breach of the levee. From the above results, we graded the characteristics of the satellites by their observational bands and spatial resolution.
\end{abstract}

\section{INTRODUCTION}

\subsection{General Instructions}

From the 9th to the 11th September 2015, the Kanto and Tohoku regions were hit by record-setting rainfall brought by Typhoon No. 18 (Etau) and the stropical storm to which it was downgraded. As a result of these heavy rains, the breach of levees, floods, and landslides occurred throughout Kanto and Tohoku regions (GSI, 2016) (MLIT, 2016). In Japan, this disaster was officially named the 'Kanto-Tohoku Deluge of September 2015'.

In Joso City in Ibaraki Prefecture, located 50km north-east of Tokyo, for example, a levee on the lower reaches of the Kinugawa River was breached, and approximately $40 \mathrm{~km} 2$ of neighbouring areas, including urban areas of the city, were inundated.

In this disaster caused by the heavy rainfall, the damaged areas were repeatedly observed by a number of different SAR satellites. Imagery data of the levee before the breach were obtained from ALOS-2 PALSAR-2 and Sentinel-1. In addition, observations were also made on the 11th September when the flood was most widespread by ALOS-2 PALSAR-2 and COSMO-SkyMed.

SAR data, which can usually identify water bodies with accuracy, were used in many cases to extract the extent of inundation, and these data provided various kinds of information used to understand situations in the damaged areas (Yamada, 2008) (Yamaguchi, 2012). In most case examples, however, the analysis was carried out using only a single type of SAR data, and the number of studies that used a combination of multiple types of SAR data was limited.

Many different SAR satellites are currently in operation, and it is expected that different SAR data would be used together for disasters. Technically, these data are obtained using different observational bands and with different spatial resolutions, and their unique physical features can make a difference in the extraction of inundation. For this reason, grading sensors' features and possible effects would be beneficial in initial analysis for future disasters.

Accordingly, in this study, focusing on the flood damages in Joso City in Ibaraki Prefecture, we estimated the extent of inundation using multiple SAR satellites and examined their varied results depending on observational bands. We further examined the potential utilization of combined different SAR data for initial responses to disasters.

\section{THE SITUATION RELATING TO THE KANTO- TOHOKU DELUGE OF SEPTEMBER 2015}

From the 9th to the 11th September 2015, a wide area within the Kanto and Tohoku regions of Japan were hit by torrential rains (in excess of $300 \mathrm{~mm}$ over a 24-hour period) brought by Typhoon No. 18 (Etau) that made landfall in Japan and Typhoon No. 17 (Kilo) that approached off the Pacific coast. The heavy rainfall caused the breach of levees in a number of places followed by floods and landslides

In particular, due to the concentration of the heavy rainfall in the upstream areas of the Kinugawa River, a tributary of the Tonegawa River that flows through the Kanto region, Joso City located between the Kinugawa and Kokaigawa Rivers experienced severe damages. For example, approximately 40 $\mathrm{km} 2$ of residential areas were inundated as a result of the river bank overtopping and the breaches of the levee.

In this study, we estimated the extent of inundation using SAR data for areas in and around Joso City in Ibaraki Prefecture. The time sequence of the disasters, such as the river levee overtopping and the breach of the levee, as well as the observations by SAR satellites before and after the breach are shown in Table 1. At the same time, the data specifications 
of the SAR satellites that made the observations are shown in Table 2 .

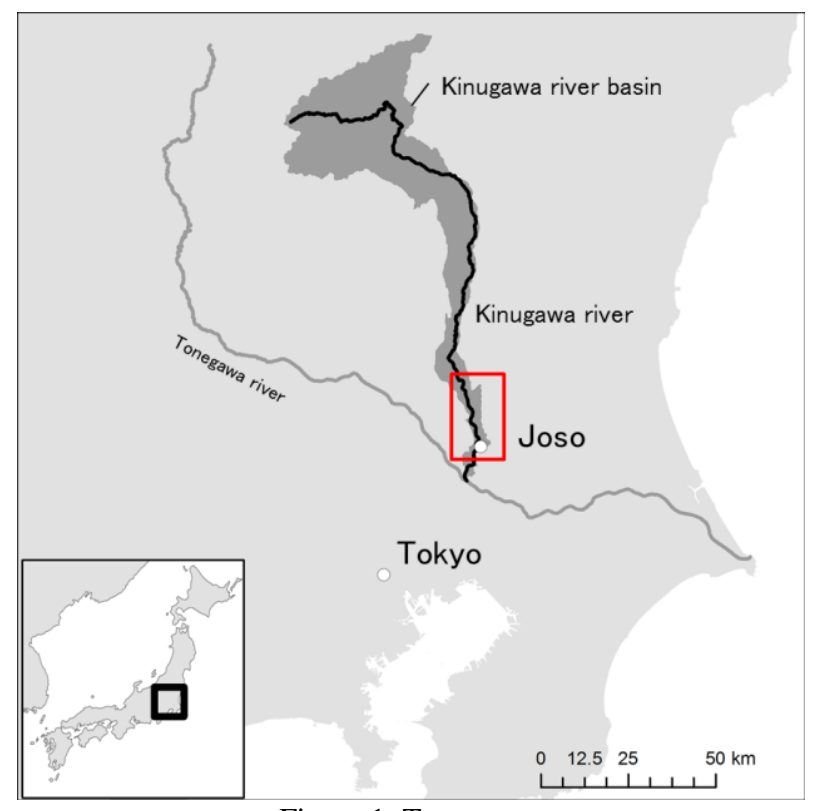

Figure 1. Target area

Table 1. Time sequence of observations and disasters

\begin{tabular}{cl|l} 
Date & Time & \multicolumn{1}{c}{ Events } \\
\hline $2015 / 9 / 10$ & $5: 40$ & Observations by Sentinel-1 \\
$2015 / 9 / 10$ & $6: 00-$ & Overflow in Kinugawa River basin \\
$2015 / 9 / 10$ & $11: 42$ & Observations by ALOS-2 PALSAR-2 \\
$2015 / 9 / 10$ & $12: 50$ & Breach of the levee in Joso City \\
\hline $2015 / 9 / 11$ & $17: 12$ & Observations by COSMO-SkyMed \\
$2015 / 9 / 11$ & $22: 56$ & Observations by ALOS-2 PALSAR-2
\end{tabular}

Table 2. Data specifications for SAR satellites used

\begin{tabular}{|l|l|l|l|l|l|}
\hline & Obs. Date & Orbit & Off nadir & Mode & Pol. \\
\hline Sentinel-1 & $9 / 105: 40$ & Descending & $34.7^{\circ}$ & $\begin{array}{l}\text { Interferometric } \\
\text { Wide swath }\end{array}$ & VV \\
\hline ALOS-2 PALSAR-2 & $9 / 1011: 42$ & Descending & $35.4^{\circ}$ & Stripmap HIMAGE & $\mathrm{HH}$ \\
\hline COSMO-SkyMed & $9 / 1117: 12$ & Descending & $51.56^{\circ}$ & Stripmap HIMAGE & $\mathrm{HH}$ \\
\hline ALOS-2 PALSAR-2 & $9 / 1122: 56$ & Ascending & $35.4^{\circ}$ & Ultrafine & $\mathrm{HH}$ \\
\hline
\end{tabular}

\section{ESTIMATION OF EXTENT OF INUNDATION AFTER THE BREACH}

First, the extent of the inundation was extracted using COSMO-SkyMed and ALOS-2 PALSAR-2 data on the 11th September, the day after the breach, when the extent of the inundation was at its most widespread. The specifications of the data used are shown in Table 3.

Table 3. Data specifications or SAR satellites used to estimate the extent of the inundation after the breach of the levee

\begin{tabular}{|c|c|c|c|c|c|}
\hline & Band & Obs. Date & Orbit & Off Nadir & Mode \\
\hline COSMO-SkyMed & $\mathrm{X}$ & 9/11 17:12 & Descending & $51.56^{\circ}$ & Stripmap HIMAGE \\
\hline ALOS-2 PALSAR-2 & $\mathrm{L}$ & $9 / 1122: 56$ & Ascending & $35.4^{\circ}$ & Ultrafine \\
\hline
\end{tabular}

\subsection{Method}

For verification, the extent of inundation announced by the Geographical Survey Institute as of 13:00 JST on the 11th September was used as reference data . (2)

The target analysis area was an area of approximately $60 \mathrm{~km} 2$ between the Kinugawa and Kokaigawa Rivers, including approximately $30 \mathrm{~km} 2$ of inundated areas.
For classification of the inundated areas, a binary classification was used with a threshold of backscatter coefficient. The threshold determined for the classification was a threshold that achieved the highest classification accuracy within the target analysis area. The highest classification accuracy was achieved at the backscatter coefficients of $-15.6 \mathrm{~dB}$ for COSMOSkyMed and -13.6 dB for ALOS-2 PALSAR-2.

\subsection{Results and discussions}

The results of inundation extraction are shown in Figure 2, while the results of accuracy assessment are summarized in Table 4. The results of the accuracy assessment for COSMOSkyMed and ALOS-2 PALSAR-2 were $72.6 \%$ and $66.1 \%$ respectively.

Table 4. Results of accuracy assessment (a) COSMO-SkyMed

\begin{tabular}{|c|c|c|c|}
\hline & \multicolumn{2}{|c|}{ Reference Data } \\
\hline & & Inundation & Other \\
\hline \multirow{2}{*}{$\begin{array}{c}\text { Classified } \\
\text { Data }\end{array}$} & Inundation & $29.8 \%$ & $6.4 \%$ \\
\hline & Other & $20.9 \%$ & $42.8 \%$ \\
\hline & & Total & $72.6 \%$ \\
\hline
\end{tabular}

(b) ALOS-2 PALSAR-2

\begin{tabular}{|c|c|c|c|}
\hline & \multicolumn{2}{|c|}{ Reference Data } \\
\hline & & Inundation & Other \\
\hline \multirow{2}{*}{$\begin{array}{c}\text { Classified } \\
\text { Data }\end{array}$} & Inundation & $29.8 \%$ & $13.0 \%$ \\
\hline & Other & $21.0 \%$ & $36.3 \%$ \\
\hline & & Total & $66.1 \%$ \\
\hline
\end{tabular}

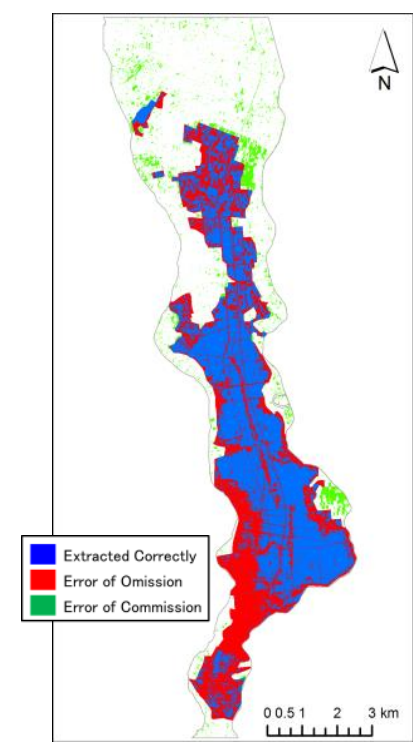

(a) COSMO - SkyMed 2015/9/11 17:12 JST

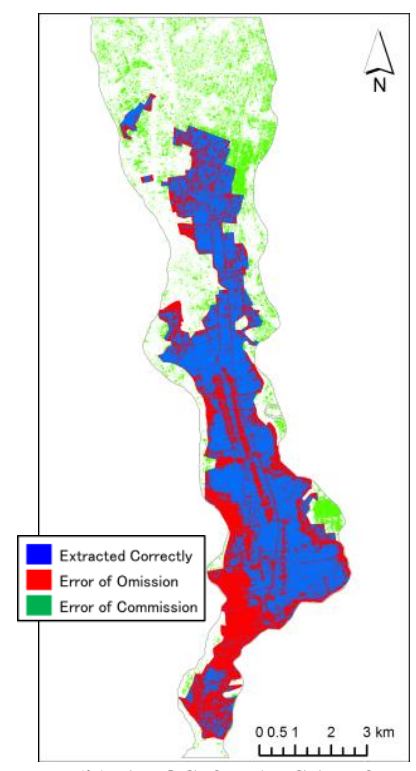

2015/9/11 22:56 JST (b) ALOS-2 PALSAR-2

Figure 2. Results of the inundation extraction after the breach of the levee

For both satellites, urban areas of Joso City, located in the southern part of the entire target area, had a high backscatter coefficient, and this made it difficult to correctly extract the flooded urban areas as inundated areas. The results indicated that regardless of observational bands, it is difficult to accurately extract the state of inundation in urban areas using SAR data. 


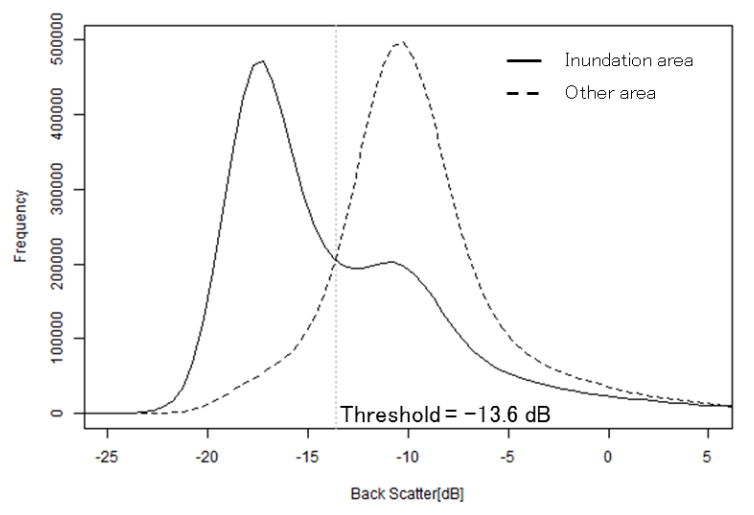

(a) COSMO-SkyMed

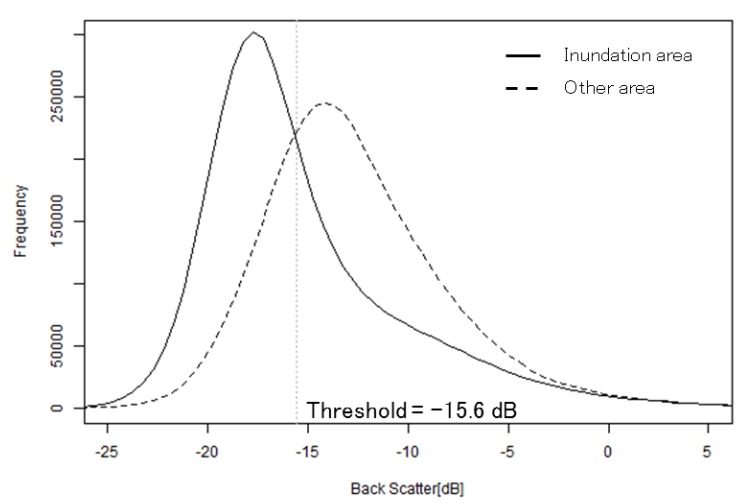

(b) ALOS-2 PALSAR-2

Figure 3. Histograms of backscatter coefficient for inundated areas and other areas

In the results of inundation extraction by COSMO-SkyMed, the histogram of the backscatter coefficient showed a good degree of separation of inundated areas and other areas, and the degree of accuracy was relatively high.

However, a number of inundated crop lands were classified as non-inundated areas. For this, shallow paddies probably appeared above the surface of the water, and this situation increased the backscatter coefficient. This also possibly caused the bimodality appeared in the histogram of the inundated areas. The observation period corresponded to the middle of the rice harvest season, and both paddies before and after harvesting were located in a mixed manner. Unlike paddies before the harvesting, the state of inundation in paddies after the harvesting were well classified.

In the results of inundation extraction by ALOS-2 PALSAR-2, on the other hand, inundated areas not only in paddies after the harvesting but also in those before the harvesting were extracted. It is possible that because ALOS-2 PALSAR-2 has a long observation wavelength, the microwave penetrated flooded rice and captured the state of inundation.

However, the results also showed that many non-inundated areas were classified as inundated areas because of the low backscatter coefficient due to the limited influences from crops. In addition, the degree of separation of inundated areas and other areas was low in the histogram, and the degree of accuracy was also low.

\section{ESTIMATION OF EXTENT OF INUNDATION FROM IMAGES TAKEN JUST BEFORE THE BREACH}

Next, we attempted to estimate the extent of inundation using Sentinel-1 and ALOS-2 PALSAR-2 data taken immediately before the breach of the levee. Both observations have data taken on the same orbit at two orbits earlier in a usual condition. The inundated areas were extracted based on the difference in backscatter coefficient between the two satellite imagery.

The data used in the differential analysis are shown in Table 5.

Table 5. Data used in differential analysis

\begin{tabular}{|c|c|c|c|c|c|c|}
\hline & \multirow[b]{2}{*}{ Band } & \multicolumn{2}{|c|}{ Observation Date } & \multirow[b]{2}{*}{ Orbit } & \multirow[b]{2}{*}{ Off Nadir } & \multirow[b]{2}{*}{ Mode } \\
\hline & & Before & After & & & \\
\hline Sentinel-1 & \begin{tabular}{|l|l}
$\mathrm{C}$ \\
\end{tabular} & $8 / 175: 40$ & $9 / 105: 40$ & Descending & $34.7^{\circ}$ & IW \\
\hline ALOS-2 PALSAR-2 & $\mathrm{L}$ & $8 / 13 \quad 11: 42$ & $9 / 10 \quad 11: 42$ & Descending & $35.4^{\circ}$ & Ultra Fine \\
\hline
\end{tabular}

\subsection{Method}

To extract inundation, a binary classification was used with a threshold from the difference in backscatter coefficient between the usual condition and the situation after the breach.

To determine the threshold, the standard deviation in difference in backscatter coefficient of non-inundated areas was calculated, and areas where the decrease of the backscatter coefficient was 2 бor greater were classified as inundated areas. For non-inundated areas, an area of $25 \mathrm{~km} 2$ in the southwest part of the entire target area that were less affected by heavy rain within the satellite imagery was selected, and standard deviations for this selected area were calculated.

\subsection{Results and discussions}

The results of the differential analysis are shown in Fig. 4. As there is no reference data available for the inundated area before the breach of the levee, it is not possible to compare the degree of accuracy. However, as the rainfall reached its peak from the 9th to the early hours of the 10th of September, agricultural lands at low altitudes were possibly inundated.

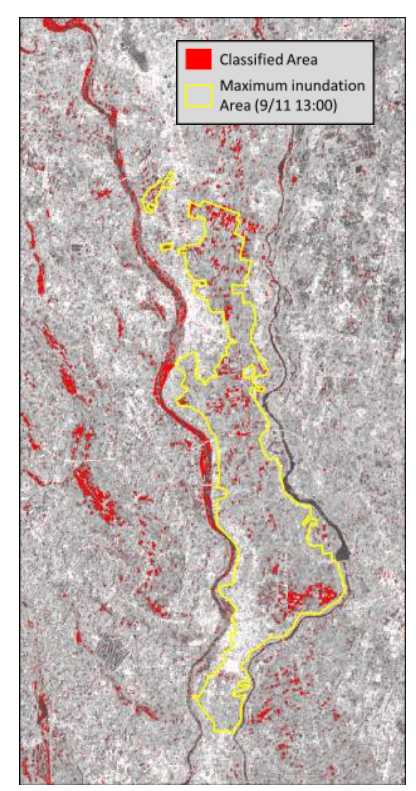

(a) Sentinel-1

2015/9/10 5:40 JST

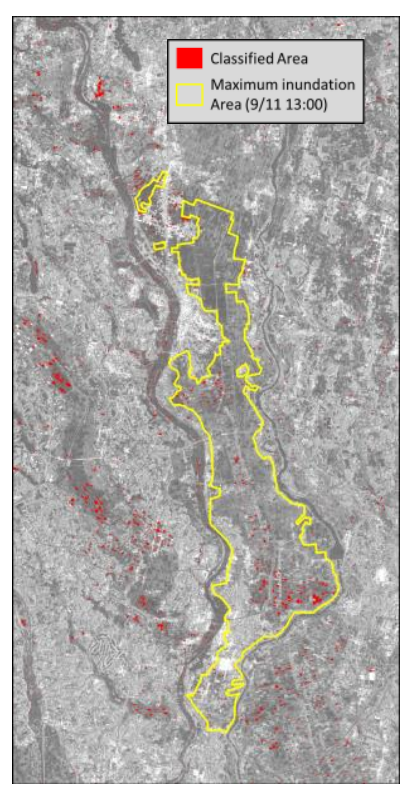

(b) ALOS-2 PALSAR-2 2015/9/10 11:42 JST
Figure 4. Results of differential analysis 
Sentinel-1 data indicated that the width of river increased and that the water level rose. They also showed that agricultural lands at low altitudes were flooded before the levee was breached. In addition, the IW mode of Sentinel-1 has a wide swath and can capture the whole Tonegawa River Basin, including the Kinugawa River, at a time. The IW mode data indicated that, in the upper reaches of the Tonegawa and Kinugawa Rivers, reservoirs were inundated and that their water level also increased (Figure 5).

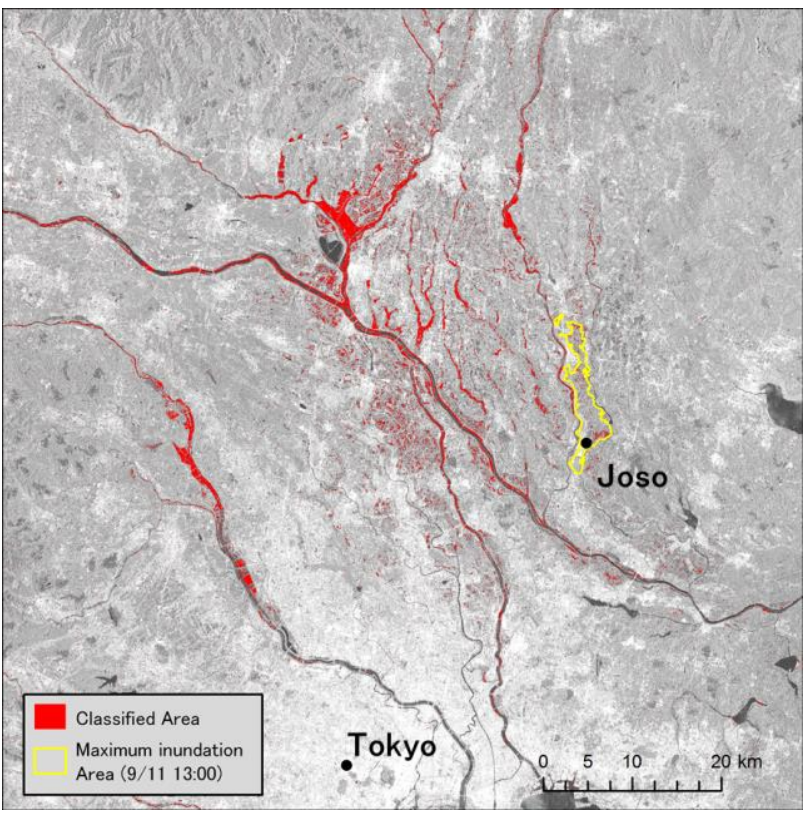

Figure 5. State of flooding in the upper reaches of the Tonegawa River by Sentinel-1

2015/9/10 5:40 JST

For ALOS-2 PALSAR-2, on the other hand, because observations were made six hours after the observations by Sentinel-1, it was assumed that the extent of the inundation expanded. However, the results showed the actual extent of the inundation extracted by ALOS-2 PALSAR-2 was smaller than the extent of inundation extracted by Sentinel-1. It is possible that because L band, which has a long wavelength, usually shows low backscatter coefficient for agricultural lands and grasslands regardless of the existence of water bodies, this resulted in a small difference in backscatter coefficient between the usual condition and the situation after the breach, and that this small difference in backscatter coefficient influenced on the narrow extent of inundation.

Furthermore, because of the strong reflections that were thought to be Bragg scattering at normal time, crop lands that show a large difference were also found outside the inundation areas.

\section{DIFFERENT CHARACTERISTICS BY OBSERVATIONAL BANDS AND THEIR POTENTIAL UTILIZATION FOR INITIAL RESPONSE}

Using the above results, the different features of the observational bands of the SAR satellites and their possible utilizations were analyzed.

The specifications of data used in this study, COSMOSkyMed, Sentinel-1, and ALOS-2 PALSAR-2 satellites are shown in Table 6.
Table 6. Data specifications of satellites used

\begin{tabular}{|l|c|l|l|l|}
\hline & Band & \multicolumn{1}{|c|}{ Mode } & Resolution & Swath \\
\hline COSMO-SkyMed & X & Stripmap HIMAGE & $3 \mathrm{~m}$ & $50 \mathrm{~km}$ \\
\hline Sentienel-1 & $\mathrm{C}$ & Interferometric Wide Swath & $20 \times 5 \mathrm{~m}$ & $250 \mathrm{~km}$ \\
\hline ALOS-2 PALSAR-2 & $\mathrm{L}$ & Ultrafine & $3 \mathrm{~m}$ & $50 \mathrm{~km}$ \\
\hline
\end{tabular}

First, COSMO-SkyMed has a high spatial resolution and also the highest accuracy in identifying the extent of inundation. The constellation of four satellites makes many observations and can be effectively used for initial response to disasters. However, due to the shorter wavelength and greater sensitivity, it is difficult to distinguish inundation on shallowly flooded agricultural lands or urban areas.

Second, Sentinel-1 periodically makes observations with a wide swath, and this feature makes it possible to understand the entire situation. However, due to the low spatial resolution, this satellite is not suitable for detailed analysis. In addition, the observations are made according to its observation plan only, and this situation makes it difficult to use this satellite for initial response to disasters.

Third, ALOS-2 PALSAR-2 offers a number of data archives for areas within Japan, and because of the many observation angles, the number of opportunities for observations can be increased. However, due to the long observation wavelength and the low sensitivity to agricultural lands, it is strongly affected by factors other than inundation.

In this study, the threshold to extract the extent of inundation was determined based on the reference data and standard deviations. In emergent circumstances, it is assumed that thresholds will be set in an arbitrary manner. In that case, it will be necessary to carry out an analysis taking the above characteristics into account.

\section{CONCLUSIONS}

In this study, we examined the SAR satellites of the Kinugawa River Basin at the time of the Kanto-Tohoku Deluge of 2015 and analyzed their inundation extraction by different SAR data.

In the extraction of inundation after the breach of the levee, COSMO-SkyMed showed the accuracy of $72.6 \%$, while ALOS2 PALSAR-2 indicated the accuracy of $66.1 \%$.

The extent of inundation were extracted by difference of backscatter coefficient using the data taken by Sentinel-1 and ALOS-2 PALSAR-2 before the breach of the levee, and the comparison analysis results showed that the extent of inundation expanded after the breach of the levee.

From the above results, we graded the characteristics of the satellites by their observational bands and spatial resolution.

There are plans to launch different kinds of SAR satellites in the future, and it is expected that the number of opportunities to utilize multiple SAR satellites in combination as initial response to disasters will increase. We think that grading the characteristics of each type of satellite will be beneficial for the effective use of SAR satellites.

\section{REFERENCES}

Geospatial Information Authority of Japan: On the damage caused by the heavy rains from Typhoons 18 and 17 (The Kanto-Tohoku Deluge of September 2015), http://www.gsi.go.jp/BOUSAI/H27.taihuu18gou.html. 
Ministry of Land, Infrastructure, Transport and Tourism: On the damage caused by the heavy rains from Typhoons 18 and 17 (The Kanto-Tohoku Deluge of September 2015), http://www.mlit.go.jp/saigai/saigai_150909.html.

Yamada, Y., 2008. MORPHOLOGICAL ANALYSIS OF FLOOD INUNDATED REGIONSIN PADDY AREAS USING ALOS/PALSAR DATA AND ITS DISTRIBUTION ON THE GOOGLE EARTHDESIGN OF THE FUTURE DISASTER MANAGEMENT SYSTEM (FDMS). The International Archives of the Photogrammetry, Remote Sensing and Spatial Information Sciences, 37(B4), pp. 1117-1122.

Yamaguchi, Y., 2012. Disaster Monitoring by Fully Polarimetric SAR Data Acquired With ALOS-PALSAR.

Proceedings of the IEEE, 100(10), pp. 2851-2860.

Revised June 2015 